\title{
¿Agresiones de la altura y degeneración fisiológica? La biografía del "clima" como objeto de investigación científica en Colombia durante el siglo xix e inicios del xx
}

High-Altitude Aggressions and Physiological Degeneration? "Climate" Biography as an Object of Scientific Inquiry in Colombia during the 19 th Century and the Early 20 $0^{\text {th }}$ Century

Agressões da altura e degeneração fisiológica? A biografia do "clima" como objeto de pesquisa científica na Colômbia durante o século XIX e inícios do XX

Stefan Pohl-Valero, PhD'

Recibido: marzo 10 de 2015• Aprobado: junio 21 de 2015

Doi: dx.doi.org/10.12804/revsalud13.especial.2015.05

Para citar este artículo: Pohl-Valero S. ¿Agresiones de la altura y degeneración fisiológica? La biografía del "clima" como objeto de investigación cientifica en Colombia durante el siglo xix e inicios del xx. Rev Cienc Salud 2015; 13 (esp): 65-83. Doi: dx.doi.org/10.12804/revsalud13.especial.2015.05

\section{Resumen}

Objetivo: mostrar el papel que tuvo la Fisiología experimental en la forma de entender los efectos del clima de alturas sobre el funcionamiento del cuerpo humano y las posibilidades de progreso de la Nación colombiana a lo largo del siglo XIX y principios del Xx. Desarrollo: se explora la trasformación del concepto del clima como objeto de investigación científica en el período estudiado, a partir del análisis de investigaciones sobre capacidad respiratoria, nutrición y metabolismo, química sanguínea y funcionamiento del corazón en habitantes de la cordillera Oriental de los Andes colombianos. Conclusiones: más allá de una historia institucional o disciplinar de la Fisiología, se muestra que algunas prácticas de Fisiología experimental desempeñaron un papel importante en los procesos de representación de la Nación, del territorio y de la población colombiana. Los habitantes de las alturas andinas ya no fueron entendidos solo en términos raciales y capacidades innatas, sino también en términos de clases sociales y transformaciones orgánicas. Se intentó compensar el supuesto proceso de "degeneración fisiológica", que disminuía la eficiencia de los cuerpos trabajadores de las alturas, por medio de una "alimentación racional".

Palabras clave: clima, raza, progreso, Fisiología, Colombia.

\footnotetext{
1 Escuela de Medicina y Ciencias de la Salud y Escuela de Ciencias Humanas de la Universidad del Rosario, Colombia. Este artículo es resultado del proyecto de investigación "Estudio comparativo sobre la historia de la Fisiología en América Latina". Correo electrónico: stefan.poh|@urosario.edu.co
} 


\begin{abstract}
Objective: To show the role of experimental physiology in the way of understanding the effects of high-altitude climates on the functioning of the human body and the possibilities of progress in Colombia throughout the 19th century and the early 20th century. Development: The transformation of the climate concept as an object of scientific inquiry is explored over the studied period. This is done by analyzing investigations on respiratory capacity, nutrition and metabolism, blood chemistry and heart function in people of the eastern range of the Colombian Andes. Conclusions: Beyond an institutional or disciplinary history of physiology, this article shows that some practices of experimental physiology played a role in the process of representing country, territory, and population. The inhabitants of the Andean highlands were understood not only in terms of race and innate abilities, but also in terms of social classes and organic transformations. The idea that there was a supposed process of "physiological degeneration", decreasing the efficiency of high-altitude workers, was tried to compensate through a "rational diet".
\end{abstract}

Keywords: Climate, Race, Progress, Physiology, Colombia.

\title{
Resumo
}

Objetivo: mostrar o papel que teve a fisiologia experimental na forma de entender os efeitos do clima de alturas sobre o funcionamento do corpo humano e as possibilidades de progresso da nação colombiana ao longo do século XIX e princípios do Xx. Desenvolvimento: Explora-se a transformação do conceito do clima como objeto de investigação científica ao longo do período estudado, a partir da análise de pesquisas sobre capacidade respiratória, nutrição e metabolismo, química sanguínea e funcionamento do coração em habitantes da cordilheira oriental dos Andes colombianos. Conclusões: para além de uma história institucional ou disciplinar da fisiologia, mostra-se que algumas práticas de fisiologia experimental jogaram um papel importante nos processos de representação da nação, o território e a população colombiana. Os habitantes das alturas andinas já não só foram entendidos em termos raciais e capacidades inatas, mas também em termos de casses sociais e transformações orgânicas. A ideia de que existia um suposto processo de "degeneração fisiológica", que diminuía a eficiência dos corpos trabalhadores das alturas, foi tentado de compensar através de uma "alimentação racional".

Palavras-chave: Clima, raça, progresso, fisiologia, Colômbia.

\section{Introducción}

En 1909, el médico Jorge Martínez Santamaría, discípulo de una de las figuras centrales de la "Medicina Tropical" en Colombia, Roberto Franco, parecía dar carta de defunción a un tema que había apasionado a investigadores desde finales de la Colonia y que había ayudado a forjar un sentimiento de tradición científica nacional (1). Este tópico no era otro que el efecto del clima sobre la salud de los seres humanos y sobre las posibilidades de progreso de las poblaciones. En efecto, al preguntarse por las razones de la "degeneración de la especie humana en la zona intertropical y la dificultad de la aclimatación de la raza blanca" en estas zonas, Martínez señalaba: 
[...] por mucho tiempo los ardores del clima llevaron todo el peso de la responsabilidad, y se necesitó el transcurso de muchos años para que la ciencia viniera a decir su última palabra sobre este asunto de primordial importancia para la humanidad (cursivas propias) (2, p. 1).

Para Martínez, el desarrollo de la teoría del germen y su explicación acerca de cómo se transmitían diferentes enfermedades era la clave para entender la "degeneración de la raza", más allá del clima y superar la estigmatización del trópico:

Hace muy pocos años que principia la obra de redención para los trópicos, demostrando con lujo de hechos que son las enfermedades que allí reinan las responsables de su decadencia y la ninguna participación que el clima tiene en el asunto (2, p. 3).

Su estudio sobre la anemia tropical en Colombia fue premiado en las celebraciones del primer centenario de la República colombiana en 1910 y, al tenor del valor simbólico nacionalista de este aniversario, parecía representar un "nuevo comienzo" de la Nación en su camino a la civilización y al progreso (3). En este caso, sería un nuevo comienzo de la Medicina y la salud pública basado en la Bacteriología $(1,4)$.

No obstante, en el mismo contexto de efervescencia nacionalista y de sensación de una vuelta a comenzar tras la última guerra civil del país (la Guerra de los Mil Días) y la pérdida de Panamá, otros actores históricos seguían preocupados por entender los efectos del clima en las posibilidades de progreso de la Nación. Por ejemplo, el ingeniero Miguel Triana, quien desempeñó un papel importante en las celebraciones del centenario, articulaba de una manera particular un discurso climático producido por criollos ilustrados de finales de la Colonia - civilización en las tierras altas y frías; barbarie en las tierras bajas y calientes- ${ }^{2}$ con uno fisiológico que empezaba a tomar fuerza en la forma de conceptualizar el cuerpo e intervenirlo para su mejor funcionamiento. En un corto artículo titulado "La Sociología de la montaña", Triana destacaba que, a pesar de que en la altiplanicie andina "la locomoción es fatigosa, donde el corazón invierte mayor cantidad de esfuerzo para distribuir la sangre en las diversas regiones del organismo humano y donde la temperatura gélida impone al labriego para la producción agrícola mayor suma de trabajo", esta era el lugar en donde mejor se podía aprovechar la "multitud de fuerzas que la montaña esconde". Las condiciones climáticas y fisiológicas de las alturas, aseguraba Triana, eran las que habían forjado en los serranos sus amplias capacidades de trabajo y un carácter "valiente, parsimonioso, perseverante y pensador", a diferencia de los "hijos de la llanura" que "son más débiles en todo sentido que éstos" (6, s. p.).

Así, además de retomar el mencionado imaginario climático de progreso y orden social - la superioridad de los serranos frente a la inferioridad de los habitantes de las tierras bajas-, la "Sociología de la montaña" propuesta por Triana también apuntaba a una cuestión que la Fisiología experimental había convertido en objeto de investigación sistemática desde la segunda mitad del siglo XIX: ¿ cuáles son los efectos de las grandes alturas en el funcionamiento del cuerpo y cuáles son los mecanismos de adaptación a estas condiciones? La aseveración

\footnotetext{
2 Este modelo fue propio de la Nueva Granada (lo que hoy llamamos Colombia) y contrastó con el de otros lugares de América Latina. Por ejemplo, en Perú se construyó una representación geográfica que distinguía tres regiones: - la costa, la sierra y la jungla - asociadas, respectivamente, con lo blanco civilizado, lo indígena inferior y lo salvaje (5).
} 
de que la "locomoción es fatigosa" y que "el corazón invierte mayor cantidad de esfuerzo" en lugares como el altiplano andino se desprendía de estudios que relacionaban el llamado mal de altura (fatiga, náuseas, dificultad para respirar, etc.) con el aire rarificado de las montañas (7). En particular, la baja presión del oxígeno en el aire circundante de las alturas y la consecuente baja oxigenación de la sangre de sus habitantes se convirtió en la punta de lanza de investigadores europeos y americanos para discutir ahora en nuevos términos y motivados por diversos intereses (colonialistas, económicos, nacionalistas), si la altura era un factor de "degeneración racial", ya que afectaba las capacidades físicas y mentales o si, por el contrario, existían mecanismos de regulación - como el aumento de glóbulos rojos o de la frecuencia respiratoriaque permitían refutar la idea de que las alturas representaban entornos hostiles para la vida humana, para la civilización y el progreso de sus poblaciones (8-11).

Desde una perspectiva disciplinar, en la que se entiende a la Fisiología experimental como un campo científico acotado y autónomo que se configuró en Alemania y Francia en la segunda mitad del siglo XIX y luego se difundió a otros contextos ${ }^{3}$ la historia de la Ciencia y la Medicina en Colombia ha señalado que la práctica médica local no se interesó por una concepción fisiológica del cuerpo humano hasta bien entrado el siglo XX. Estas narrativas han ayudado a construir un relato que encuadra la práctica médica dentro de especialidades y disciplinas científicas bien delimitadas y definidas de antemano. Así, la historiografía local ha señalado que a finales del siglo XIX se pasó de una mirada anatomoclínica — preocupada por detectar las lesiones orgánicas como causas de las enfermedades- y de una

3 Kremer ofrece un panorama general de la historiografía de la Fisiología en Europa (12). medicina geográfica que clasificaba las enfermedades según la altitud y el clima a una mirada etiopatológica que, gracias a la teoría del germen, buscó el agente causal de la enfermedad en los análisis bacteriológicos. Acerca de la transformación de la Medicina en Colombia en el cambio de siglo, se ha destacado que la mentalidad fisiopatológica - que "ve la enfermedad como un desarreglo funcional, una alteración energéticomaterial que compromete a todo el organismo" (13, p. 68) - no logró integrarse con las otras miradas en el quehacer médico colombiano (la antomoclínica y la etiopatológica) debido a la falta de laboratorios y de formación de los médicos en Ciencias Naturales, así como por "la hegemonía que continuaba ejerciendo el modelo anatomoclínico en la mente de los profesores de las escuelas de medicina del país" (14, pp. 101-102).

No obstante, desde finales del siglo XIX, los médicos locales estaban muy interesados en entender el funcionamiento del cuerpo humano y sus adaptaciones según las condiciones y variaciones del medio exterior, que transitan por medio de y difuminan este tipo de fronteras disciplinares y conceptualizaciones históricas. A partir de la última década de ese siglo, se empezó a investigar sobre los cuerpos de habitantes de las cordilleras andinas colombianas con diversos instrumentos, para medir cuestiones como cantidad de glóbulos rojos, capacidad torácica, frecuencia respiratoria, trabajo del corazón o cantidad de urea en la orina, cuyos resultados fueron comparados con valores medios elaborados en Europa. Así, es posible argumentar que el clima, más que desaparecer como objeto de interés médico — como lo aseguraba el médico Martínez y la historiografía tradicional- persistió en la agenda de investigación local en los albores del siglo xx, pero ahora enmarcado en un nuevo esquema conceptual, epistemológico y metrológico, representado por pesquisas fisiológicas experimentales. Esta 
nueva mirada del papel del clima en la salud y la enfermedad ayudó a configurar nuevas perspectivas sobre lo social, toda vez que le asignó nuevos significados a la noción de raza y a las posibilidades de progreso nacional en términos de regeneración fisiológica.

Este artículo es un primer intento de abordar la historia de la Fisiología en Colombia, no desde una óptica institucional o disciplinar, sino a partir del rastreo de la forma como el estudio científico del clima fue incorporando diversas concepciones y prácticas fisiológicas y el rol de esta transformación en el modo de entender e intervenir la naturaleza y la sociedad en Colombia durante el siglo xIX y principios del $\mathrm{xx}$. En otras palabras, el presente texto es un esfuerzo por hacer la "biografía de un objeto científico" (el clima), que permita vislumbrar cómo su existencia y sus trasformaciones, así como las realidades naturales y sociales que ayudó a producir, se articularon en "redes de significación cultural, prácticas materiales y deducciones teóricas" (15, p. 13) que son difícilmente clasificables en los límites de una disciplina científica o especialidad médica. Para situaciones de debilidad institucional y de poca especialización disciplinar como fue el caso de la práctica científica colombiana de finales del siglo XIX, parece sugerente preguntarse por cómo se construyó el objeto científico del clima y su articulación con maneras particulares de entender e intervenir la realidad. Esta perspectiva se complementa con los trabajos históricos que se han preguntado por la llegada e institucionalización de la Fisiología experimental en contextos latinoamericanos y por las condiciones locales que ayudaron a definir sus agendas y estilos de investigación $(16,17) .{ }^{4}$

4 Una sugerente reflexión sobre alternativas para superar el modelo difusionista de la ciencia (centro-periferia), a partir del caso del desarrollo de la Fisiología de alturas en México y Perú, lo aporta Cházaro (18).

\section{El influjo del clima sobre los seres} organizados

En 1910, el médico Juan N. Corpas exploró en detalle los efectos del clima de Bogotá en la "fisiología y la patología del hombre" (19). La investigación, resultado de su tesis para obtener el grado en Medicina, de la Universidad Nacional, era una clara muestra de que el clima - en particular, el clima andino- seguía arraigado en la agenda de investigación del gremio médico nacional. Como lo comentaba el presidente de la tesis, este trabajo señalaba "el camino de nuevas investigaciones de sumo interés para el mejor conocimiento de la especial patología de las ciudades andinas, capítulo muy importante de la Medicina nacional" (19, p. 5). Esta ciudad se encuentra ubicada en una extensa meseta o un altiplano de la cordillera Oriental de los Andes colombianos y, según los datos de Corpas, se sitúa "a los $4^{\circ} 35^{\prime}$ 55" de latitud Norte (Garavito) y a los $76^{\circ} 34^{\prime} 8^{\prime \prime}$ de longitud occidental de París" y a una elevación sobre el nivel del mar de "2640 [m] según Garavito" (19, p. 7).

Como parte de esta "medicina nacional", el trabajo de Corpas combinaba una larga tradición de estudios meteorológicos y climáticos que se venían desarrollando desde finales del siglo XVIII en las regiones andinas, con la práctica anatomoclínica que, de acuerdo con la historiografía, había caracterizado el quehacer médico colombiano durante buena parte del siglo XIX y también con las nuevas teorías bacteriológicas y fisiológicas para entender la enfermedad y el funcionamiento del cuerpo a grandes alturas. Como él mismo lo indicaba:

$[\ldots]$ hemos dividido nuestro trabajo en dos partes: en la primera nos ocupamos $[\ldots]$ de las propiedades físicas, químicas y bacteriológicas de la atmósfera de las localidades altas, y particularmente de Bogotá; en la segunda parte trataremos de la influencia 
que, sobre algunas funciones del organismo humano, tienen esas condiciones atmosféricas, y el sello especial que imprimen a la etiología, la patogenia y el tratamiento de algunas enfermedades (19, p. 6).

En la primera parte de su tesis, Corpas ubicaba su trabajo como la continuación de un campo de investigación que se había iniciado a finales del siglo XVIII y en el que viajeros naturalistas locales y extranjeros, inmersos en amplias redes de comunicación, habían aportado un gran acervo de información para caracterizar las condiciones climáticas de los Andes. Los nombres de Caldas, Humboldt, Mutis, Boussingault, etc. y sus respectivas expediciones científicas eran continuamente mencionados, al igual que trabajos más recientes elaborados por militares, astrónomos, matemáticos y médicos locales. Para el estudio de la naturaleza del aire también presentaba una larga genealogía de investigaciones de químicos y físicos sobre este asunto y destacaba la forma de calcular "el peso del oxígeno contenido en un litro de aire", según la altura. También mencionaba algunos análisis químicos del aire de Bogotá, realizados por investigadores europeos a mediados del siglo XIX y toda una serie de investigaciones que relacionaban la cantidad de diferentes elementos presentes en la atmósfera de acuerdo con la altitud. Por su parte, se lamentaba de no poder aportar nada a la "microbiología de la atmósfera en las localidades elevadas", dado que se carecía de un "laboratorio de higiene municipal" en donde pudiera hacer el análisis bacteriológico del aire (19, p. 34-35).

Con todo, Corpas no estaba caracterizando una tradición científica en términos disciplinares o institucionales, sino en torno a un objeto de investigación científica: el clima. De hecho, la Climatología era presentada por él como un campo de estudio que comprendía "la atmos- ferología, la meteorología, la geografía física, la fisiología geográfica y la patología comparada" y, más aún, Corpas señalaba lo que varios autores habían entendido por "clima" a lo largo de la historia. Empezó por Hipócrates, quien lo definía como "el conjunto de las circunstancias físicas propias a una localidad, en relación con sus seres vivientes"; Humboldt, que lo caracterizaba como "un conjunto de líneas isotermas"; Caldas, que lo entendía no solo como:

[...] el grado de calor y de frío de cada región, sino también la carga eléctrica, la cantidad de oxígeno, la presión atmosférica, la abundancia de ríos y de lagos, la disposición de las montañas, las selvas y los pastos, el grado de población o los desiertos, los vientos, las lluvias, el trueno, las nieblas, la humedad, etc. (19).

Fonssagrives y Proust lo entendían como "la fórmula meteorológica de un país" y "la constitución general de la atmósfera de un lugar" y, por último, Lesieur lo definía como el "conjunto de las regiones que tienen los mismos caracteres generales desde el triple punto de vista meteorológico, fisiológico y patológico" (19, p. 16). Varios de los apartados de la investigación de Corpas seguían la misma estructura a la planteada un siglo antes por el criollo ilustrado Francisco José de Caldas en su famoso artículo "El influjo del clima sobre los seres organizados" (20). A partir de una definición amplia de clima, se iban analizando los aspectos de la vida de las personas que estarían sujetos a su influjo, en particular, en las alturas.

Desde una perspectiva de construcción de identidad nacional y de tradiciones científicas propias, la figura de Caldas tuvo un rol central en los discursos de los científicos de todo el siglo XIX (21). Para Corpas, como para tantos otros, Caldas no solo simbolizaba el inicio de 
la República, en tanto héroe del panteón de los próceres de la independencia, sino también era el precursor de una ciencia nacional que abogaba por conocimientos producidos de forma local y la posibilidad de cuestionar el saber europeo ilustrado. Y uno de los principales temas que utilizó Caldas para ello fue justamente el clima.

Personajes de la Ilustración como el naturalista francés Georges Louis Leclerc, conde de Buffon (1707-1788) o el filósofo holandés Cornelius de Pauw (1739-1799) destacaron en sus estudios que las características climáticas del continente americano y su desarrollo geológico, en términos temporales, explicaban la "inferioridad" de sus habitantes y de su naturaleza. Ahora era el clima - y no Dios- el que permitía explicar las capacidades y el grado de civilización de las poblaciones y regiones del planeta. Al ser el continente americano mucho más joven que el europeo, argumentaba Buffon, su clima y sus rasgos geológicos y geográficos no solo explicaban que el tamaño y la fertilidad de los animales americanos fueran menores a los europeos o que sus habitantes fueron pasivos e incapaces de dominar a la naturaleza, sino también la idea de que los mismos europeos que permanecían por largo tiempo en este continente tendían a sufrir una "degeneración" de sus facultades que los volvía como niños incapaces de alcanzar la tan celebrada "mayoría de edad" que Kant había acuñado en esa misma época para referirse a las características del hombre ilustrado blanco y europeo $(22,23)$.

Los criollos ilustrados del Nuevo Reino de Granada - la región que hoy conocemos como Colombia- hicieron una particular apropiación de estas teorías climáticas, por medio de las cuales destacaron su carácter ilustrado al inscribirse en este saber europeo y eurocéntrico, pero a la vez defendieron sus aspiraciones de poseer una autoridad legítima sobre la naturaleza y la sociedad americana $(22,23)$. Así, para Caldas, el problema del "influjo del clima sobre los seres organizados", según las teorías europeas, no era su desprecio a los nativos americanos, sino la generalización y el desconocimiento - por falta de observación personal- de las diferencias geográficas y climáticas del nuevo mundo. Además, afirmaba que las regiones elevadas del Nuevo Reino de Granada ofrecían las condiciones idóneas para la actividad intelectual, moral y física que los europeos consideraban como exclusivas de su geografía. Académicos como Mauricio Nieto y Santiago Castro-Gómez han señalado que, en sus inicios, el proyecto de construcción de Estado-Nación republicano en Colombia tuvo un importante referente del discurso climático europeo, en el que se reafirmó una supuesta superioridad étnica criolla frente al resto de la población americana y en el que se construyó un modelo de civilización e identidad nacional basado en el altiplano andino $(22,23)$. A lo largo del siglo XIX, esta particular caracterización climática y racial de las posibilidades de progreso de la nueva república de Colombia permeó a profundidad los discursos políticos y científicos de la élite local $(24,25)$.

Por ejemplo, varios de los participantes de la Comisión Corográfica (1850-1859) —una de las principales empresas científicas colombianas del siglo XIX que pretendía modernizar la administración pública al obtener conocimientos detallados de las regiones del país- hicieron detalladas descripciones de las características de los habitantes de las regiones, de acuerdo con el clima de cada una de ellas. Se relacionó toda una serie de características humanas a determinados climas (25-27). Las tierras frías y templadas representaron el lugar donde habitaban personas sanas, vitales, trabajadoras y dispuestas al progreso, mientras las tierras calientes propiciaban la pereza, el estancamiento y enfermedades. Como lo comentara Felipe Pérez, 
uno de los continuadores de la Comisión tras la muerte de su director:

El desarrollo i lonjevidad del hombre varía
según el clima i el terreno en que habita. Los
habitantes de nuestros ardorosos valles se
desarrollan con precocidad; pero en lo jene-
ral carecen de vigor i lozanía, i no llegan a
una edad avanzada, especialmente si el cli-
ma es húmedo [...]. En las tierras altas, por
el contrario, el hombre es fuerte i vigoroso, i
aunque su desarrollo es lento, goza de salud
y vive largos años (28, p. 179-80). ${ }^{5}$

Manuel Ancízar, miembro de la Comisión desde sus inicios, señalaba también que el indígena de las tierras altas era "sobrio cual ningún otro, [...] obediente, laborioso y honrado" y, en general, que las costumbres, los trajes, los modales, los comportamientos y las actitudes de las personas variaban según el clima, de forma análoga a como variaba la "temperatura atmosférica" (30, p. 107). En todas estas taxonomías geográficas de la población, el cuerpo humano se relacionaba con el clima como un proceso de afuera hacia adentro. El medio externo ejercía su influjo sobre las capacidades intelectuales, morales y físicas de las personas, lo que a su vez se reflejaba en su configuración anatómica. Por ejemplo, era muy discutido el llamado ángulo facial de Camper que, según Caldas, proporcionaba una fuente verdadera para dar cuenta del "grado de civilización" de las personas (20, p. 145). Este ángulo fue uno de los antecedentes de anatomía comparada en el que se basó la Frenología, ciencia fundada en la idea de que cada parte del cerebro tiene su propia función que determina el comportamiento del individuo y sus facultades mentales

5 Esta cita provenía de un manual de geografía publicado en 1852 (29) y que Pérez reproducía en su texto de 1865. y que la estructura de este es perceptible a partir de la forma del cráneo (31). El mismo Ancízar mencionaba mediciones frenológicas que había hecho en tumbas indígenas en sus travesías con la Comisión Corográfica y observó que el cráneo de los indios motilones "presentan la frente comprimida y plana, predominando las prominencias correspondientes a los órganos de la industria, el orgullo y las pasiones físicas" (30, p. 467).

Se pensaba también que varias enfermedades, como fiebres, seguían una distribución de acuerdo con la altitud y el clima. Como ha expresado Mónica García, el neohipocratismo y la geografía de las plantas desarrollada por Humboldt y por Caldas, así como la medicina geográfica francesa, fueron referentes importantes en la configuración de una geografía médica local a mediados del siglo XIX. Desde esta perspectiva se aseveró que el clima ya no solo era predisponente del origen de ciertas enfermedades, sino una causa específica y determinante (32). Incluso las primeras investigaciones que se preguntaban por la fisiología de los diferentes pobladores de Colombia estuvieron caracterizadas por esta misma visión ambientalista que servía para caracterizar las razas y el origen de las enfermedades con base en su distribución climática.

En efecto, Antonio Vargas Vega, uno de los primeros médicos colombianos en enseñar Fisiología experimental en Bogotá, publicó en 1865 un trabajo sobre "Estudios de climatolojia comparada-Elevación del suelo" (33). En este estudio, Vargas se proponía describir los efectos de las alturas andinas sobre el funcionamiento de la vida de diferentes razas y las patologías características de estas regiones. En particular, se preguntaba por los efectos de la altura en los procesos de respiración y digestión de grupos clasificados como blancos, mestizos e indígenas. Según algunas observaciones clínicas de auscultación a blancos y mestizos en la sabana 
de Bogotá, Vargas aseguraba que su ritmo de respiración y su capacidad torácica reflejaba una "debilidad relativa" frente a la función respiratoria de los indígenas del altiplano. Aunque no mencionaba haber hecho mediciones al respecto, indicaba que estos tenían un pecho más ancho y fuerte (en general, mayor musculatura), lo que les permitía adaptarse mejor a la actividad física en las alturas. En cuanto a la digestión, las observaciones de Vargas indicaban que la de los blancos era mucho menos dinámica que las de los indígenas, los cuales eran descritos como "naturalmente sobrios". Esto implicaba que los indígenas requerían una alimentación mucho más frugal y menos nutritiva que la de los blancos para el buen funcionamiento de su organismo y que una dieta abundante incluso podría debilitar físicamente a los indígenas. A partir de estas características anatómicas y fisiológicas, Vargas indicaba que los blancos estaban predispuestos a la vida sedentaria e intelectual, mientras los indígenas tenían una capacidad natural para el trabajo manual del cultivo de la tierra. En consecuencia, dado que en altiplano andino "el hombre [blanco] no puede soportar en estas alturas un trabajo sostenido: sus fuerzas se agotan i su constitución se deteriora en breve tiempo $[\ldots]$ ", era natural que "el trabajo abrumador [fuera] el patrimonio de la raza india", así como en las zonas bajas los "negros" constituían la "raza trabajadora" (33, pp. 1-2). Con esto, Vargas propuso una clasificación racial de las capacidades de trabajo de indígenas, negros y blancos que naturalizaba, por medio del clima y sus respectivas características anatómicas y fisiológicas, una organización jerarquizada de la sociedad que venía desde la Colonia $(34,35)$.

El trabajo de Vargas representaba una mirada geográfica de la Fisiología profundamente conectada con la forma de entender el clima y la realidad social a mediados del siglo XIX. Al igual que los miembros de la Comisión Corográfica, Vargas emplazaba las características anatómicas de las razas en una distribución climática altitudinal (de tierras altas y frías y de tierras bajas y calientes), las cuales indicaban características fisiológicas diferenciadas. El funcionamiento de la vida (la fisiología) estaba subordinado a la estructura anatómica de los cuerpos, ${ }^{6}$ estructura que se dejaba clasificar de acuerdo con la geografía. Era el clima el que, en última instancia, determinaba el funcionamiento de los fenómenos vitales de las razas. Como lo aseveraba uno de los principales representantes de la Geografía Médica en Colombia, Domingo Esguerra, "el hecho de que las localidades ejercen una influencia fisiológica [...] es incontestable, pues se revela por la diferencia de constitución i de funcionalidad que se nota en el hombre en los distintos países" (37, p. 43).

Esta forma de estudiar el clima no solo respondió a las teorías científicas imperantes de la época (determinismo geográfico, mirada ambientalista de las enfermedades, subordinación de la Fisiología a la Anatomía) o a los instrumentos y las mediciones disponibles (barómetros, termómetros, estetoscopios, instrumentos anatómicos, altura, temperatura, humedad, intensidad de la respiración, ángulo de camper, capacidad torácica, etc.); también reflejó un estilo de conocer y producir conocimiento científico particular. Como se ha analizado en otro

6 Vargas definía a la Fisiología de la siguiente forma, lo que denotaba todavía una larga tradición que entendía a esta ciencia como subordinada al estudio anatómico: "La Fisiolojía es una ciencia experimental. Su objeto es el estudio del mecanismo de los fenómenos vitales: su punto de partida [es] el conocimiento de la estructura anatómica de los órganos i el análisis físicoquímico de las propiedades de la materia organizada; su fin [es] dirigir las manifestaciones de los fenómenos de la vida" (36, p. 220). 
lugar, la Geografía Física de Caldas, las actividades de la Comisión Corográfica, la Geografía Médica y la Fisiología de Vargas respondían a una forma de dar cuenta de los fenómenos basada en las capacidades personales del observador, en mediciones realizadas in situ, en la sensibilidad por los rasgos locales del objeto de estudio y en una aproximación holística y estética que no buscaba la particularidad de casos concretos, sino formas típicas o arquetipos (38). Fue dentro de este estilo de ciencia que la "fisiología geográfica", como la había denominado Corpas en su definición de la climatología, adquiría en el trabajo de Vargas una concepción particular que contrastaba con la suya, propuesta cuarenta años después.

\section{Influencia del clima de la} altiplanicie sobre las combustiones humanas

El trabajo de Corpas de 1910 reflejaba una forma diferente de abordar el estudio de la Fisiología en relación con el clima. A diferencia de Vargas y su Fisiología Geográfica, el estudio de Corpas basaba su fuente de conocimiento en "hechos" producidos en el laboratorio y contrastados con valores estandarizados y normalizados y no en una mirada holística y ambientalista obtenida en el lugar "natural" donde ocurrían los fenómenos. Frente al hecho de que en la altura de Bogotá el organismo recibía menor cantidad de oxígeno que en altitudes inferiores, Corpas expresaba que "el organismo se ingenia para obtener todo lo que necesita, por lo cual lo vemos aumentar el número de las respiraciones, el de las pulsaciones, el número de glóbulos rojos, su riqueza globular, etc." (19, p. 24). Desde esta perspectiva, la influencia del clima sobre los cuerpos y sus capacidades incluía una serie de mecanismos de compensación del organismo humano que, analizados en el laboratorio, aportaban nuevas capas de significación a nociones como raza, normalidad, degeneración o progreso.
Un tema discutido por Corpas fue el de los glóbulos rojos y la cantidad presente en la sangre que debería considerarse "normal". Corpas afirmaba que, dadas las condiciones climáticas de Bogotá, en teoría, el número de glóbulos rojos debería ser mayor en sus habitantes que en los residentes al nivel del mar. Las investigaciones europeas proponían un valor medio de 5 millones por milímetro cúbico. El primer inconveniente frente a esto era que una investigación desarrollada en Colombia por el médico Jorge Vargas Suárez en 1899 sobre la "sangre normal" había demostrado que los habitantes de Bogotá tenían un número mucho menor de glóbulos rojos (39). No obstante, otro médico de la época, el ya mencionado Jorge Martínez Santamaría, cuya "competencia" era alabada por Corpas, había obtenido resultados preliminares sobre veinte personas sanas y diez curadas de anemia y concluyó que la "cifra normal" en Bogotá era de más de 5 millones glóbulos (5.239 para los sanos y 5.638 para los curados) (19, p. 47). En todo caso, indicaba Corpas, la idea de "poliglobulia" o "hiperoglobulia" —esto es, el mecanismo de regulación fisiológica para compensar la falta de oxígeno en las alturas - era una cuestión muy debatida por la comunidad científica europea de la época y no por todos aceptada. Corpas mencionaba los trabajos del médico francés François Gilbert Viault, quien aseguraba el fenómeno de la poliglobulia. Este investigador había viajado a Perú en 1889 para hacer pesquisas fisiológicas en habitantes de un distrito minero a más de 4.000 metros de altura. Las exploraciones de Viault, discípulo del fisiólogo Paul Bert, se enmarcaron en los intereses económicos y coloniales de la Fisiología europea de alturas de la época. De hecho, los Gobiernos franceses e ingleses subvencionaron investigaciones en Perú y México para conocer las posibilidades de la aclimatación de trabajadores y militares europeos en las regiones altas de estos países (8). 
Los resultados de Martínez Santamaría y los de Viault permitían a Corpas concluir que existía la poliglobulia y que se debía "a la disminución del oxígeno en la atmósfera de las alturas". También señalaba que la hemoglobina (lo que facilitaba a los glóbulos rojos una mayor o menor absorción de oxígeno), aunque no se estudió en el caso de Bogotá, debería aumentar con la altura. Las mediciones hechas por Corpas en relación con el influjo de la altura fueron pulsaciones por minuto (mayor que la media europea), tensión arterial (mayor que la media europea), trabajo del corazón (mayor que la media europea), número de respiraciones por minuto (mayor que la media europea), circunferencia del tórax (igual que la media europea), capacidad pulmonar (no parecía aumentar con la altura) y temperatura humana (menor a la media europea). Sus promedios fueron obtenidos del estudio de cien individuos diferenciados entre hombres y mujeres, sin especificar grupos raciales (19). En general, para Corpas, el funcionamiento de la vida en Bogotá lograba compensar los efectos adversos de su clima, aunque señalaba que la acción mecánica de la presión atmosférica sobre los músculos implicaba una mayor cantidad de trabajo muscular para las actividades motrices. Esta cuestión parecía explicar la razón de "la pereza habitual de los habitantes de las alturas" (19, p. 59).

El trabajo de Corpas fue revisado por el médico Calixto Torres Umaña un par de años después, en 1913, cuando investigó las capacidades metabólicas de los habitantes de Bogotá y Tunja (esta última un poco más elevada que Bogotá) (40). $\mathrm{Al}$ igual que Corpas, Torres parecía ubicarse en la tradición de los estudios del clima inaugurada por Caldas. Un elemento importante presente en las ideas de Caldas, muy poco estudiado por la historiografía, era que dentro de su concepción de clima incluía la alimentación. Como el mismo Caldas lo comentaba, "los demás agentes del clima sólo nos tocan, por decirlo así, en la corteza; los alimentos llevan sus efectos a lo más íntimo de nuestro cuerpo". Algunos alimentos, aseguraba, extenuaban y debilitaban el cuerpo mientras otros lo vigorizaban, renovaban los humores y encendían o apagaban el "fuego de las pasiones". Su frugalidad moderaba "los ímpetus terribles de la lascivia" y su exceso corrompía a las personas. Luego de presentar algunos ejemplos de esta mirada neohipocrática de la alimentación, Caldas preguntaba: “Se dudará todavía de la influencia de los alimentos sobre los seres organizados?" (20, p. 194).

El principal apartado de la investigación de Torres llevaba por título una variación del famoso texto de Caldas: "Influencia del clima de la altiplanicie sobre las combustiones humanas" y como Caldas, Torres incluía en su concepción de clima a la alimentación. El punto de inicio de la investigación de Torres era el hecho comprobado "por todos los médicos y estudiantes" de que la temperatura media corporal en Bogotá y Tunja era inferior a la "temperatura aceptada como media en Europa" (40, p. 29). Además de las cien observaciones de Corpas que corroboraban esta apreciación, Torres mencionaba otros trabajos de médicos colombianos y el suyo realizado en Tunja. Las posibles razones de esta baja temperatura las atribuía Torres a tres factores que englobaba en el concepto general de clima: 1) influencia de la temperatura ambiente; 2) influencia de la altura, y 3) influencia de la alimentación. Según Torres, la temperatura ambiente de Bogotá y Tunja no podía explicar la "baja considerable de la temperatura animal en la altiplanicie" (40, p. 30). El segundo punto se debatía con amplitud y se conectaba con aquel sobre la poliglobulia antes mencionado. Torres también citaba los trabajos de Viault y su idea de la existencia de "un mecanismo regulador o de defensa que se pone en juego a medida que la presión disminuye" 
(40, p. 31), pero a diferencia de Corpas, Torres cuestionaba las ideas de Viault y aseguraba que "lo que parece demostrado es que la hiperglobulia [de la que habla Viault] es simplemente periférica y que el número de glóbulos rojos del corazón y de los gruesos vasos no aumenta" (40, p. 31).

Los análisis de sangre hechos por Torres - para los que utilizó el numerador de Hayem y el de Thomas Zeiss para los glóbulos rojos y el aparato de Fleishl para medir la hemoglobinaparecían invertir la "ley de Viault" y corroborar los resultados del médico Jorge Vargas Suárez, de 1898: tanto los glóbulos rojos como la hemoglobina parecían más bien disminuir con la altura, por lo menos, al comparar a Tunja con Bogotá. Sus mediciones, realizadas a veintiún adultos sanos de la ciudad de Tunja, daban un promedio de 4.547.380 glóbulos rojos por milímetro cúbico y un 78\% de hemoglobina. Para el caso de Bogotá, Torres combinaba mediciones suyas con las del médico Jorge Martínez Santamaría, con un total de doscientas personas analizadas. Los promedios para Bogotá eran de 4.799.714 de glóbulos rojos y un $83,21 \%$ de hemoglobina. Torres también se preguntaba por otros medios de defensa frente al enrarecimiento del aire, como mayor capacidad torácica, número de respiraciones y de pulsaciones, pero concluía que ninguno de estos mecanismos de compensación era suficiente para garantizar el óptimo funcionamiento del organismo en las alturas (40).

Todos estos resultados le llevaron a asegurar que "nuestra raza, [...] está atacada de un principio de degeneración fisiológica que la incapacita para defenderse contra las agresiones de la altura" (41, p. 75). No obstante, según Torres, faltaba tener en cuenta un medio adicional de defensa: la alimentación. La cuestión era saber si los alimentos de la altiplanicie eran igual de nutritivos que los de otras regiones (sus análisis químicos indicaban que así era) y si la capacidad de absorción de estos nutrientes se veía afectada por el clima. Luego de hacer múltiples análisis químicos de orina, Torres llegaba a la conclusión de que existía "una insuficiencia de utilización del azoe como elemento de nutrición" $\mathrm{y}$, en términos generales, "una inactividad en las transformaciones orgánicas y especialmente en las oxidaciones" que podrían explicar la baja temperatura media de las personas y su "disminución de la superficie hemoglobínica" (40, p. 36 y 123). Las casusas de esta inactividad orgánica, sugería Torres, dependían quizás de una falta de actividad glandular encargada de secretar los fermentos destinados a producir las transformaciones orgánicas. ${ }^{7}$

En suma, Torres afirmaba que la clave para combatir la "degeneración fisiológica" detectada en los habitantes de la altiplanicie consistía en una mejor nutrición, sobre todo de proteína animal y en disminuir el consumo de chicha. Aunque los alimentos locales eran suficientemente nutritivos, la capacidad metabólica de su asimilación por parte de la población de la altiplanicie era inferior a la población europea, lo cual repercutía en una mayor disposición a adquirir ciertas enfermedades y en una menor capacidad de trabajo. Para sus investigaciones, Torres utilizó el laboratorio municipal de Bogotá, creado en 1910 como una de las secciones de la administración sanitaria de la ciudad, laboratorio que Corpas señalaba que no existía en el momento de sus investigaciones. Así como para Corpas, los individuos de quienes Torres obtenía muestras ya no representaban el tipo ideal racial de alguna región (como había sido el caso de la Fisiología Geográfica de Vargas), sino que se descomponían en "clase obrera" y "clases acomodadas" (40). La investigación de Torres fue

\footnotetext{
7 Esta idea se apoyaba en un estudio realizado por el médico Luis Felipe Calderón sobre síndromes poliglandulares en la altiplanicie (42).
} 
entendida como un aporte central para abordar "nuestros más trascendentales problemas" (40, p. 10) y de hecho fue escogida para representar a Colombia en el segundo Congreso Científico Panamericano que se realizó en 1916-1917 en Washington (41).

Diez años después, el químico Antonio María Barriga Villalba se preguntaba también por las "condiciones de vida en Bogotá", desde una perspectiva físico-química. Este investigador aseguraba sobre el clima de Bogotá:

$[\ldots]$ no es propio para el desenvolvimiento natural completo; nos falta presión y oxígeno, dos elementos que concurren a modificar tanto el doble fenómeno físico y químico de la vida, que el organismo no puede adaptarse como debiera, sino que se defiende compensándose a expensas de otros factores, como son la duración media de la vida, la actividad intelectual y el trabajo mecánico (43, p. 582).

Así, la vida en las alturas parecía connotar una inferioridad frente a regiones más "normales":

[...] por una parte, el organismo trabaja en condiciones de inferioridad; por otra, los elementos alimenticios de que disponemos, tampoco llenan las necesidades de la célula. Todo esto nos anuncia un déficit con relación a los individuos semejantes que viven en condiciones normales (43, p. 583).

Barriga conceptualizaba el funcionamiento de la vida como un proceso de búsqueda de equilibrio entre las células y el medio exterior, lo cual implicaba que el organismo requería igual cantidad de oxígeno independientemente del lugar en donde se encontrara:
Nuestra máquina humana es un conjunto de varios millones de células que viven las unas para las otras trabajando en completa armonía. Como los individuos, conjunto de sistemas, y como éstos, conjunto de órganos, las células se agrupan para formar los tejidos; y todos respiran y necesitan oxígeno para subsistir, y como siguen viviendo, y los cambios químicos de las células son constantes, se deduce que la cantidad de oxígeno debe permanecer invariable para sostener el ritmo de la plastida (43, p. 584).

Desde esta perspectiva funcional, era necesario que en las condiciones de Bogotá "el corazón fuerce la sangre a llevar a los tejidos en la misma unidad de tiempo la misma cantidad de oxígeno que en el nivel del mar". El trabajo del corazón aumentaba en la altura andina, calculaba Barriga, en un $14 \%$. Si el trabajo del corazón de un individuo en reposo en Barranquilla (una ciudad al nivel del mar) equivalía a 592 caballos de fuerza por día, en Bogotá era de 679 caballos. Además del aumento del trabajo del corazón, Barriga contemplaba otros efectos de compensación frente a la falta de oxígeno de Bogotá: aumento de los glóbulos rojos (5.630.000) y aumento de las respiraciones por minuto $(20,9) .{ }^{8}$ Aunque Barriga aceptaba la poliglobulia rechazada por Torres, sus recomendaciones para evitar una "degeneración fisiológica" o "déficit" orgánico eran idénticas: "Para reestablecer el equilibrio en el funcionamiento del organismo, en las regiones de Bogotá, es indispensable aumentar la ración alimenticia" (43, p. 586). El resto de su trabajo se dedicaba a analizar en el "recientemente creado" Laboratorio de Higiene Nacional la calidad de diversos alimentos vendidos en Bogotá, así como

\footnotetext{
8 El autor no indicaba si estos datos habían sido obtenidos por él o de otros trabajos.
} 
la calidad del agua y del aire de esta localidad. Del mismo modo que Torres y otros médicos de la época, se instaba a que el Gobierno tomara medidas de regulación alimentaria y que se establecieran dietas racionales de acuerdo con las condiciones climáticas. Como lo comentaba otro médico, con base en estadísticas del consumo de carne en las diferentes regiones del país, se observaba un "absurdo fisiológico", en tanto su consumo disminuía en la medida que aumentaba la altitud (44, p. 39).

A principios del siglo $\mathrm{xx}$, la forma de entender algunos de los problemas de la Nación siguieron estructurándose en torno al estudio científico del clima, pero enmarcado ahora en una red diferente de instrumentos, medidas, valores estandarizados, tablas estadísticas y estilos de conocer. Para captar su influjo sobre las personas, ahora el investigador tenía que recurrir, por lo menos en parte, a los hechos producidos en el laboratorio y contrastarlos con valores estadísticos normalizados. Las características raciales ya no se dejaban captar solo por una mirada holística y ambientalista de las regiones y sus habitantes, sino que dependía también del estudio en el interior del organismo, ahora llamado "laboratorio humano" y de su comparación con lo que se consideraba "normal".

En este ensamblado particular del estudio del clima se configuraron nuevas estrategias de gobierno sobre la población, ahora destinadas a la "regeneración fisiológica" de los cuerpos habitantes de las alturas. Como se ha analizado, los hábitos alimenticios de las poblaciones de las regiones de Colombia se convirtieron en un campo de estudio de Fisiología Nutricional que articuló una mirada eugenésica de la población con una concepción fisiológica-energética del organismo humano. Esto, a su vez, produjo diversas acciones de ingeniería social para intentar optimizar el funcionamiento del cuerpo trabajador en relación con su ambiente (45). El objeto científico "clima" había sufrido una transformación desde la época de Caldas, que iba mucho más allá del desarrollo de nuevas teorías sobre la enfermedad y el funcionamiento del cuerpo o de la institucionalización de la Fisiología. Incluía también una trasformación epistémica y una red metrológica global que definía nuevas reglas para producir conocimiento de la naturaleza y la sociedad y, por lo tanto, una forma diferente de aprehender la realidad, de organizarla y de intervenirla.

\section{Conclusiones}

Es evidente que, con la llegada de la Bacteriología a Colombia, la idea de que el clima era el elemento central para entender el origen y la distribución de diversas enfermedades fue revaluado. ${ }^{9}$ No obstante, desde una mirada funcional del cuerpo, su influjo siguió siendo objeto de indagación patológica. La posibilidad de un aumento de trabajo del corazón en las alturas fue relacionada con la hipertrofia cardiaca. También se propuso que "la vida continuada en la altiplanicie en la época del desarrollo predispone el retardo en la evolución de algunos órganos [infantilismo hepático] y a [algunas] insuficiencias glandulares", así como que podría modificar el metabolismo basal (42, p. 244; 47). Asimismo, se exploraron las perturbaciones nutritivas (dispepsias) de los niños de "las altiplanicies del trópico" y sus trastornos metabólicos (acidosis infantil) en relación con el "medio ambiente", las "costumbres" y las "particularidades fisiológicas raciales" (48, p. 9 y 28). Por otra parte, solo a finales de la década de 1930 se establecería un laboratorio dedicado en exclusiva a la Fisiología experimental en

\footnotetext{
9 No obstante, este proceso fue complejo y, en un primer momento, intentó articular algunos aspectos de la Geografía Médica con la Bacteriología (46).
} 
Bogotá y sus investigaciones se institucionalizarían en la universidad colombiana.

Más allá de la historia de las enfermedades y de la Fisiopatología o de la institucionalización de la Fisiología, esta incipiente exploración sobre la biografía del clima como objeto de indagación nos muestra, primero, que su estudio integró una serie de conceptos y prácticas fisiológicas muy poco estudiadas hasta el momento y segundo, que esta integración añadió nuevos elementos a las complejas imbricaciones en la forma de entender el orden natural y el orden social. A lo largo del siglo XIX y principios del XX, el clima siguió aunado a los procesos de representación de la Nación, del territorio y de la población y a sus posibilidades de civilización y progreso. La clasificación altitudinal del grado de civilización de la Nación y la jerarquización social justificada en términos climáticos propuesta por Caldas se vio reflejada en la Fisiología Geográfica de Vargas de mediados del siglo XIX. Acá, el cuerpo de las "razas" tenía unas características anatómicas y fisiológicas determinadas por el clima que eran estáticas, inamovibles.

No obstante, en los discursos y las investigaciones sobre clima y civilización después de la segunda mitad del siglo XIX se refleja una conceptualización diferente sobre la forma como se relaciona el cuerpo con el ambiente. Los mecanismos de regulación del organismo frente a las variaciones exteriores se volvieron la punta de lanza para dirimir, con mediciones hechas en el laboratorio, la inferioridad o igualdad física y mental de los habitantes de las alturas andinas frente a los europeos. Como han mostrado varios historiadores, las investigaciones de americanos y europeos sobre estas cuestiones reflejaron intereses económicos, coloniales y nacionalistas y percepciones racializadas y jerarquizadas de las poblaciones (8-11). Si para algunos europeos la altura podía ser una de las explicaciones "naturales" de la supuesta inferioridad de los habitantes de los Andes, para investigadores mexicanos y peruanos —en el marco de discursos nacionalistas e indigenistas-, la existencia de mecanismos de adaptación fisiológica fue la prueba de una "normalidad" de la "raza de las alturas". ${ }^{10}$ Para el caso colombiano, algunos investigadores señalaron la existencia de algunos de estos mecanismos — como la hiperglobuliaen los cuerpos de la altiplanicie, mientras otros los rechazaron, pero en general se relacionó el clima andino con pereza muscular, degeneración fisiológica o déficit orgánico.

Esto no quiere decir que el modelo de civilización e identidad nacional basado en el altiplano andino se hubiera invertido. A principios del siglo $\mathrm{xx}$, las tierras bajas $\mathrm{y}$ ardientes y sus habitantes seguían representando la barrera por excelencia del progreso y la civilización (49). Como expresaba Barriga, frente a las características climáticas de Bogotá:

$$
\begin{aligned}
& {[\ldots] \text { por instinto economizamos el trabajo }} \\
& \text { material por ser formas poco prácticas de } \\
& \text { nuestra energía, y asílas cosas van marchan- } \\
& \text { do, tal vez, mejor que en los climas bajos, } \\
& \text { en donde el problema del oxígeno está sus- } \\
& \text { tituido por el no menos grave de la falange } \\
& \text { de parásitos que en todo momento acechan } \\
& \text { en silencio al organismo (43, p. 586). }
\end{aligned}
$$

Tampoco quiere decir que los médicos locales carecieran de un sentido nacionalista como el señalado por los historiadores para los investigadores mexicanos y peruanos, en tanto refutaron las tesis eurocéntricas de inferioridad

10 Para algunos otros europeos, como el francés François Gilbert Viault, mencionado en este trabajo, la existencia de estos mecanismos de regulación reflejaba más bien la posibilidad de que los blancos europeos pudieran aclimatarse y colonizar las tierras altas americanas, sin detrimento de sus facultades físicas y mentales. 
andina propuestas por algunos fisiólogos franceses e ingleses. Al igual que sus colegas latinoamericanos, los colombianos abogaron por una medicina nacional y criticaron que los estudios locales se basaran en una "fisiología [europea] que no nos pertenece" (40, p. 9). Más bien, lo que muestran los casos estudiados es una nueva forma de entender la relación entre lo natural y lo social, que es inseparable en nuestro caso de la tradición local de investigación sobre clima y civilización. Con la idea general de que el clima de las mesetas andinas colombianas y sus habitantes, representaban el ideal de civilización y progreso nacional, las investigaciones fisiológicas sobre las alturas, desde finales del siglo XIX, empezaron a explorar en el laboratorio las condiciones funcionales de esos cuerpos y a interpretarlas bajo un prisma social que contrastaba con el de mediados de ese siglo.

En medio de un incipiente proceso de industrialización e ingreso al sistema capitalista global, la gran masa poblacional del altiplano cundiboyacense ya no fue entendida solo en términos raciales y capacidades innatas, sino también en términos de clases sociales y transformaciones orgánicas. Aunque se siguieron discutiendo las capacidades de blancos e indígenas en la vida de las alturas - por ejemplo, Barriga Villalba señalaba que los "caracteres raciales" de los indígenas del altiplano eran los más adecuados para "subsistir" en esas regiones y que "[n]osotros que tenemos más del treinta por ciento de sangre indígena, no tenemos mucho que temer, nuestro organismo trabaja en mejores condiciones" - la noción de clase se imbricó con la de raza a la hora de pensar en las posibilidades de progreso y productividad (43, p. 581-582). Independientemente de si eran indígenas o mestizos o cuál era su grado de aclimatación, se entendió que la "clase trabajadora" del altiplano cundiboyacense estaba sometida a un proceso de degeneración fisiológica que le impedía optimizar su capacidad de trabajo y aumentar su eficiencia y el papel de los investigadores acá estudiados fue el de, a la vez, definir este nuevo "problema social" y proponer las estrategias para resolverlo. Una alimentación racional fue la clave para revertir este supuesto problema degenerativo de las alturas. Las cuestiones de jerarquización social y modelo de civilización andino, no obstante, parecieron permanecer intactas.

\section{Agradecimientos}

Agradezco a los participantes de coloquio "Historias alternativas de la Fisiología en América Latina", realizado en la Universidad del Rosario en agosto de 2014, por sus sugerencias y críticas, así como a los dos evaluadores anónimos que revisaron el presente texto.

Financiación:

Este artículo es resultado del proyecto de investigación "Estudio comparativo sobre la historia de la Fisiología en América Latina", financiado por la Universidad del Rosario (fiur dvg-156).

\section{Referencias}

1. Quevedo E, Borda C, Eslava JC, García CM, Guzmán MP, Mejía P et al. Café y gusano, mosquitos y petróleo. El tránsito desde la higiene hacia la medicina tropical y la salud pública en Colombia 18731953. Bogotá: Universidad Nacional de Colombia; 2004.

2. Martínez Santamaría J. Contribución al estudio de la anemia tropical en Colombia. Bogotá: La Luz; 1909.

3. Castro-Gómez S. Señales en el cielo, espejos en la tierra: La exhibición del centenario y los laberintos de la interpelación. En: Castro-Gómez S, Restrepo E, Eds. Genealogías de la colombianidad. 
Formaciones discursivas y tecnologías de gobierno en los siglos XIX y XX. Bogotá: Pontificia Universidad Javeriana; 2008. p. 222-53.

4. Márquez Valderrama J. Ciudad, miasmas y microbios: la irrupción de la ciencia pasteriana en Antioquia. Medellín: Universidad de Antioquia; 2005.

5. Orlove BS. Putting Race in its Place: Order in Colonial and Postcolonial Peruvian Geography. Soc Res 1993; 60 (2): 301-36.

6. Triana M. Sociología de la montaña. El Gráfico 1913; 4 (123): s. p.

7. West J. High Life: A History of High-Altitude Physiology and Medicine. Oxford: Oxford University Press; 1998.

8. Cueto M. Excelencia científica en la periferia: actividades científicas e investigación biomédica en el Perú 1890-1950. Lima: Tarea; 1989.

9. Cházaro L. La fisiología de la respiración en las alturas, un debate por la patria: mediciones y experimentos. En: Pérez-Siller J, Cramaussel C, editores. México y Francia. Memoria de una sensibilidad común. Siglos XIX-XX. Tomo II. México D. F.: Centro de Estudios Mexicanos y Centroamericanos; 1993. p. 317-39.

10. Rodríguez de Romo AC, Padilla JR. The Mexican Response to High Altitudes in the 1890s: The Case of a Physician and his "Magic Mountain". Med Hist 2003; 47 (4): 493-516.

11. Lossio J. El peruano y su entorno. Aclimatándose a las alturas andinas. Lima: Instituto de Estudios Peruanos; 2012.

12. Kremer RL. Physiology. En: Bowler PJ, Pickstone JV, editores. The Cambridge History of Science. Volume 6. The Modern Biological and Earth Sciences. Cambridge: Cambridge University Press; 2009. p. 342-66.

13. Miranda M. La medicina colombiana de 1867 a 1946. En: Quevedo E, editor. Historia social de la ciencia en Colombia. Medicina (II). Bogotá: Colciencias; 1993. p. 15-160.

14. Quevedo E, Pérez GE, Miranda NJ, Eslava JC, Hernández ME, Acosta MC et al. Historia de la medicina en Colombia. Tomo III. Hacia una profesión liberal (1865-1918). Bogotá: Norma; 2010.

15. Daston L. Introduction. The Coming into Being of Scientific Objects. En: Daston L, editor. Biographies of Scientific Objects. Chicago: The University of Chicago Press; 2000. p. 1-14.

16. Cueto M. Andean Biology in Peru: Scientific Styles on the Periphery. Isis 1989; 80 (4): 640-58.

17. Vimieiro Gomes AC. Uma ciência moderna e imperial: A Fisiologia brasileira no final do século XIX (1880-1889). Rio de Janeiro: Editora Fiocruz; 2013.

18. Cházaro L. La soledad "local" y el cosmopolitismo nacional. La fisiología respiratoria de americanos y europeos en el contexto colonial, siglo XIX. En: Gorbach F y López Beltrán C, editores. Saberes locales. Ensayos sobre historia de la ciencia en América Latina. Michoacán: El Colegio de Michoacán; 2008. p. 123-45.

19. Corpas JN. La atmósfera de la altiplanicie de Bogotá: en algunas de sus relaciones con la fisiología y la patología del hombre. Bogotá: Imprenta de Medina e Hijo; 1910.

20. Caldas FJ. El influjo del clima sobre los seres organizados. En: Semanario del Nuevo Reino de Granada. Bogotá: Biblioteca Popular de Cultura Colombiana; 1942 [1808]. p. 136-96.

21. Obregón D. Sociedades científicas en Colombia. La invención de una tradición, 1859-1936. Bogotá: Banco de la República; 1992.

22. Castro-Gómez S. La hybris del punto cero. Ciencia, raza e ilustración en la Nueva Granada (1750-1816). Bogotá: Pontificia Universidad Javeriana; 2005. 
23. Nieto Olarte M. Orden natural y orden social. Ciencia y política en el semanario del Nuevo Reyno de Granada. Madrid: CSIC; 2007.

24. Larson B. Trials of Nation Making. Liberalism, Race, and Ethnicity in the Andes, 1810-1910. Cambridge: Cambridge University Press; 2004.

25. Arias J. Nación y diferencia en el siglo XIX colombiano. Orden nacional, racialismo y taxonomías poblacionales. Bogotá: Uniandes; 2005.

26. Sánchez E. Gobierno y geografía: Agustín Codazzi y la Comisión Corográfica de la Nueva Granada. Bogotá: Banco de la República; 1998.

27. Restrepo O. Un imaginario de la Nación. Lectura de láminas y descripciones de la Comisión Corográfica. Anu Colomb Hist Soc Cult 1999; 26: 30-58.

28. Pérez F. Jeografía jeneral de los Estados Unidos de Colombia. París: Librería de Rosa y Bouret; 1865.

29. Cuervo AB. Resumen de la jeografía histórica, política, estadística i descriptiva de la Nueva Granada. Para el uso de las escuelas primarias superiores. Bogotá: Torres Amaya; 1852.

30. Ancízar M. Peregrinación de Alpha. Bogotá: Imprenta de Echeverría Hermanos; 1853.

31. Nofre D. En el centro de todas las miradas: una aproximación a la historiografía de la frenología. Dynamis 2006; 26: 93-124.

32. García M. Las fiebres del Magdalena. Medicina y sociedad en la construcción de una noción médica colombiana, 1859-1886. Bogotá: Universidad Nacional de Colombia; 2006.

33. Vargas Vega A. Estudios de climatolojia comparada —Elevación del suelo. Gaceta Médica 1865; 1:1-2.

34. García M. Clima, enfermedad y raza en la medicina colombiana del siglo XIX. En: Hochman G, Palmer S y Di Lisia Lima S, editores. Patologías de la patria. Enfermedades, enfermos y Nación en América Latina. Buenos Aires: Lugar Editorial; 2012. p. 59-74.

35. Hering Torres MS. Orden y diferencia. Colombia a mediados del siglo XIX. En: Restrepo Forero O, editor. Ensamblando heteroglosias. Bogotá: Universidad Nacional de Colombia; 2013. p. 375-93.

36. Vargas Vega A. Programa de fisiolojia. Anales de la Universidad Nacional de los Estados Unidos de Colombia 1869; 2 (9): 220-40.

37. Esguerra D. Memoria sobre las fiebres del Magdalena. Santana: Imprenta de D. Díaz; 1872.

38. García M, Pohl-Valero S. The Science of the Naturalist Traveler and Laboratory Science: Two Styles of Knowledge Production in 19th Century Colombia. En prensa 2015.

39. Vargas Suárez J. La sangre normal y la sangre en las anemias. Bogotá: Imprenta Rivas; 1899.

40. Torres Umaña C. Sobre metabolismo azoado en Bogotá. Bogotá: Arboleda \& Valencia; 1913.

41. Torres Umaña C. La nutrición en la altiplanicie de Bogotá. En: Swiggett GL, editor. Proceedings of the Second Pan American Scientific Congress. Section VIII Part 2. Washington: Government Printing Office; 1917. p. 52-104.

42. Calderón LF. Sindromas poliglandulares de la altiplanicie. En: Segundo Congreso Médico de Colombia. Tomo I. Bogotá: Escuela Tipográfica Salesiana; 1913. p. 223-46.

43. Barriga Villalba AM. Condiciones de vida en Bogotá. Revista del Colegio Mayor de Nuestra Señora del Rosario 1927; 22 (220): 581-93.

44. Cotes M. Régimen alimenticio de los jornaleros de la sabana de Bogotá: estudio presentado al Primer Congreso Médico Nacional de Colombia. Bogotá: La Luz; 1893.

45. Pohl-Valero S. "La raza entra por la boca": Energy, Diet, and Eugenics in Colombia, 1890-1940. Hispanic Am Hist Rev 2014; 94 (3): 455-86. 
46. García M. Geografía médica, bacteriología y el caso de las fiebres en Colombia en el siglo XIX. Hist Crit 2012; 46: 66-87.

47. Gnecco Mozo F. Introducción al estudio del metabolismo basal en Colombia. Bogotá: s. e.; 1932.

48. Torres Umaña C. Problemas de nutrición infantil. París: Franco-Ibero-Americana; 1924.

49. Jagdmann AT. Del poder y la geografía: La cartografía como fuente de legitimación en Colombia [tesis doctoral]. Berlín: Universidad Libre de Berlín; 2006. 